\title{
Diarrhoeal Diseases in Children Under Five Years Exhibited Space-Time Disparities and Priority Areas for Control Interventions in Rwanda
}

\section{LADISLAS NSHIMIYIMANA ( $\sim$ ladisn05@gmail.com)}

Rwanda Biomedical Center https://orcid.org/0000-0002-5551-6990

Peris Monchari Onyambu

Mount Kenya University Rwanda

Erigene Rutayisire

Mount Kenya University Rwanda

Research

Keywords: Diarrhoeal, children under five, spatiotemporal, temperature, rainfall

Posted Date: May 8th, 2020

DOI: https://doi.org/10.21203/rs.3.rs-26476/v1

License: (c) (i) This work is licensed under a Creative Commons Attribution 4.0 International License. Read Full License 


\section{Abstract}

Background: The Diarrhoeal diseases remain to be a public health concern despite the existence of preventive measures and developing are the most affected. It affects more children less than five years compared to the rest of the population. The burden of childhood diarrhoea varies with geographical area and time bound. A part from this variation, the link between climate change and diarrhoea among under-five children has not been well understood. This study aims to determine the trends, spatial temporal and seasonal characteristics of diarrhoea diseases among Rwandan under-five children using routine Health Management Information System (HMIS) data from 2014 to 2018.

Methods: Data on cases of diarrhoeal diseases in children under-five years were extracted from HMIS for a period of 5 years. The Rwanda Meteorology Agency provided climatology data including daily minimum and maximum temperature, and daily rainfall. Incidence rate were calculated to examine the trend, and excess hazard was assessed to determine the risk and likelihood for the occurrence of cases. Linear regression was used to assess relationship between climatology variables and the occurrence of diarrhoea.

Results: 1,012,827 new diarrhoeal diseases episodes were reported. Excess risk was noticed in 40\% of country's districts. We found a statistically significant positive and negative relationship between diarrhoeal disease, and maximum temperature and mean monthly rainfall respectively $(p<0.001)$. Increase in one millimeter of rainfall was associated with decrease of 14 cases of diarrhoea while increase of one degree Celsius of maximum temperature was associated with an increase of 15 diarrhoea cases.

Conclusion: More districts with risk of diarrhoea were remarked which require targeted control intervention. Furthermore, significant association between diarrhoea case and climate dynamics was observed. This call for the public attention to climate changes which affect health especially children aged less than five years. Key words: Diarrhoeal, children under five, spatiotemporal, temperature, rainfall

\section{Background}

Diarrhoeal diseases still a public health problem, Low-income, and Middle-Income Countries (LMICs) being most affected. The occurrence of diarrhoea can range from moderate to severe case, severe diarrhoea can lead to excessive loss of fluid hence cause dehydration [1]. Diarrhoeal diseases results mostly among others from rotavirus infection as viral infection. Major responsible bacteria include Shigella, Salmonella, campylobacter as well as Yersnia. Responsible protozoa include giardia, entamoeba, and cryptosporidium [2].

The global analysis of the morbidity diarrhoea reported an estimated 2.39 billion cases worldwide in 2015 [3], children below five years and old adult are at high risk [4]. In 2016, it was reported to the be the 9th among the top cause of death throughout the world (1.4 million death), 2nd and the 6th major cause of death in LMIC respectively [5]. In the investigation conducted in 2016 on the burden of diarrhoea from 195 countries, collaborators found it to be the 8th major cause of death in all age and was responsible of $1,655,944$ deaths. It was ranged as the fifth in children aged younger than five years (446,000deaths) [6]. Roughly, 1.7 billion diarrhoea cases occur annually and diarrhoea is responsible of more than a half million children death each year [1]. Diarrhoea was reported to be a major cause of Disability Adjusted Life of Years (DALYS) specifically in younger children and causing 71.59 million DALYS [4].

Through the global assessment of diarrhoeal diseases burden for the period of 26 years (1990-2016), Rotavirus was most common etiology of diarrhoea amongst children aged less than 5 years (U5) (128,515 deaths). The most common risk factors attributed to diarrhoeal diseases are poor sanitation, unsafe water and child undernutrition [6]. Although sanitation have been improved in most of countries worldwide, 780 million have limited access to portable water and 2.5 billion experience difficulties to access cleanliness services [7].

Children with high risk are those with suppressed immunity and undernourished [6]. Globally, diarrhoea is a major cause of malnutrition among children under five (U5) years. Children in LMICs experience around three events of diarrhoea per year, hence preventing appropriate nutrients intake necessary for child growth [1].

Diarrhoeal diseases affect more children U5 years in Rwanda; the National Institute of Statistics of Rwanda (NISR) reported gastro-intestinal diseases as the 9th among the top causes of death in 2014-2015 [8] and the second leading cause of morbidity in U5 children in health centers in 2016 after acute respiratory infection [9]. The morbidity of childhood diarrhoeal diseases has been observed in several studies to be associated with climate changes [10-14]. Furthermore, geographical and time disparities of diarrhoeal diseases were reported in different studies [10, 15-18].

By determining diarrhoeal diseases clusters in space and time in Rwanda, and by considering climatic changes can support to detect priority affected areas and opt for evidence-based informed interventions at each level within the Rwandan health system. Adopting such decisions would enhance prevention and control interventions, effort and proper resources allocation for diarrhoeal diseases interventions. Despite, the importance of such evidences, there is a scarcity of studies focusing on spatial, time and seasonal pattern of diarrhoeal diseases in Rwanda. In response, this study was conducted to determine the trend of diarrhoeal diseases in Rwandan children aged below five years, space-time, and seasonal characteristics using routine HMIS data.

\section{Methods}




\section{Study settings}

The study included countrywide data from all health facilities and all Community Health Workers located in all 30 districts.

\section{Study Design}

The study design consisted of an ecological study employing retrospective data analysis.

\section{Data Sources}

Data were extracted from the Health Management Information System (HMIS) for new cases of diarrhoeal diseases from January 1 st, 2014 to December 31st, 2018. The Rwanda Meteorology Agency provided climatology data including daily minimum and maximum temperature, and daily rainfall from the January 1st, 2014 to December 31st, 2017.

\section{Data analysis}

Data were cleaned and summarized using Microsoft Excel to compute monthly incidence of diarrhoeal disease, monthly average of temperature and rainfall from each district. The trend of annual and monthly incidence was computed for the five years with reference to seasonal patterns and time specifications. Incidence rate was calculated per 1,000 children younger than five years. The trend of cases and clustering data was presented to determine changes related to temperature and rainfall and trend changes of diarrhoea across the country.

To determine the risk and likelihood for the occurrence of diarrheal diseases, an excess hazard was computed; this hazard was computed by taking the ratio of observed over expected cases per each district and were plotted on the Rwandan districts map by the aid of the Geographical Information System (ArcGIS). The number of expected cases was determined using the following formula: $E[c]=p * C / P$. Where $c$ corresponds to the cases observed, $\mathbf{p}$ refers to the population per each district, $\mathbf{C}$ and $\mathbf{P}$ consist of the sum of cases as well as population.

Scan statistics was completed using SaTScan software version 9.6. A retrospective analysis was completed using the Discrete Poisson model, by which the likelihood corresponding to a specific window was used for determining districts with clusters. The most likely cluster was determined by considering the window with the maximum likelihood (scanning for high rate). The population at risk was considered to be $=50 \%$ and with population defined in the max circle size $=50 \%$. To determine the level of significance, a Monte Carlo $p$-value and a critical value were attributed to each cluster. The significance threshold was set at $p$-value of less than $0.05(p<0.05)$ and Log Likelihood Ratio (LLR) greater than the critical value. The following formula was used:

$\left(\frac{c}{E[c]}\right)^{c}\left(\frac{C-c}{C-E[c]}\right)^{c-c} I_{0}$

Where $\mathbf{C}$ corresponds to the sum of cases, $\mathbf{c}$ refers to the cases detected in the window, $\mathbf{E}[\mathbf{c}]$ refers to the predicted sum of cases by adjusting the covariate under null hypothesis, $\mathrm{C}$-E[C] consists of the predicted sum of cases and $\mathrm{I} O \mathrm{O}$ is the function indicator.

The interpretation of the findings was based on the following:

When I) was equal or greater than one, the window was considered having more excess cases than expected under a null hypothesis $\left(\mathrm{H}_{0}\right)$, assuming a distribution of disease cases with equal risk in all district without clustering and equal distribution of cases throughout the year or month, and if less than one was interpreted as a window with less cases than expected [19].

Scan statistics consisted of a purely spatial, purely temporal and spatiotemporal cluster analysis by each district and five years. Significance was reported using the Monte Carlo $p$-value with a threshold $p<0.05$ and critical values less than the Log Likelihood Ratio (LLR).

Seasonal patterns analysis was completed using purely temporal analysis by connecting monthly average from January to December, for the period of five years on incidence of diarrhoeal disease and for the period of four years for climatology data. A time-series analysis was plotted comparing diarrhoeal diseases incidence rate variation to rainfall and temperature changes. IBM SPSS Statistics version 21 was used to develop line graphs of monthly decomposition of diarrhoea incidence, temperature and rainfall. All graphs were merged together for good visualization. Furthermore, SPSS was used to conduct linear regression analysis to assess the relationship between diarrhoeal diseases and meteorological variables. Different methods were used including stepwise, backward and forward to ascertain the existence of such relationship. The significance threshold was set at $95 \% \mathrm{Cl}$ with $\mathrm{p}<0.05$.

\section{Results}


Monthly data on diarrhoea in children under five years were retrieved from all health facilities and Community Health Workers (CHWs) located in the 30 districts for the period of 5 years between the January 1st, 2014 to December 31st, 2018. Monthly data on climate variables (temperature and rainfall) were available for 4 years from the January 1st, 2014 to December 31st, 2017. A total number of 1,012,827 new diarrhoeal diseases episodes were reported in outpatient consultations and by CHWs during the study period. The annual incidence rate per 100,000 population of children under five years as computed using SaTScan was 12,669 (12,669/100,000). The incidence showed an increasing tendency over time, with variation from district to another and in years $\left(R^{2}=0.24\right)$. The highest diarrhoea incidence rate $(329.3 / 1000)$ was found in Kirehe district, located in Eastern province in 2017, and the lowermost incidence (48.5/100) was reported in Kamonyi, Southern province in 2016 (Table 1 ).

Table 1

Annual incidence rate of diarrhoeal diseases in $<5$ years children at district level in Rwanda between the 1st January 2014 and 31st

\begin{tabular}{|c|c|c|c|c|c|}
\hline \multirow[b]{2}{*}{ District } & \multicolumn{5}{|c|}{ Incidence rate per $1000<5$ years population } \\
\hline & 2014 & 2015 & 2016 & 2017 & 2018 \\
\hline Bugesera & 102.8 & 125.7 & 100.5 & 119.5 & 108.5 \\
\hline Burera & 165.6 & 213.4 & 190.9 & 222.2 & 236.1 \\
\hline Gakenke & 130.2 & 153.5 & 160.4 & 182.8 & 177.1 \\
\hline Gasabo & 133.6 & 136.2 & 110.5 & 114.7 & 107.7 \\
\hline Gatsibo & 136.7 & 128.3 & 128.6 & 170.0 & 153.7 \\
\hline Gicumbi & 77.8 & 98.4 & 100.0 & 113.5 & 118.5 \\
\hline Gisagara & 114.9 & 157.2 & 116.8 & 155.6 & 179.2 \\
\hline Huye & 110.2 & 94.6 & 80.9 & 116.9 & 127.0 \\
\hline Kamonyi & 64.3 & 55.0 & 48.5 & 70.5 & 65.2 \\
\hline Karongi & 116.6 & 114.8 & 101.9 & 123.3 & 109.1 \\
\hline Kayonza & 141.7 & 162.8 & 111.2 & 108.8 & 78.9 \\
\hline Kicukiro & 68.9 & 74.5 & 70.3 & 78.4 & 106.3 \\
\hline Kirehe & 225.5 & 254.1 & 231.8 & 329.3 & 318.7 \\
\hline Muhanga & 64.3 & 91.4 & 77.4 & 105.6 & 108.0 \\
\hline Musanze & 121.8 & 147.4 & 161.7 & 173.3 & 215.9 \\
\hline Ngoma & 193.3 & 152.2 & 115.3 & 113.4 & 103.5 \\
\hline Ngororero & 58.2 & 67.4 & 63.3 & 79.6 & 69.4 \\
\hline Nyabihu & 99.7 & 102.2 & 99.6 & 129.5 & 166.9 \\
\hline Nyagatare & 139.6 & 141.0 & 100.0 & 136.3 & 141.3 \\
\hline Nyamagabe & 83.5 & 88.5 & 72.2 & 100.8 & 122.3 \\
\hline Nyamasheke & 101.6 & 114.0 & 119.2 & 117.7 & 134.9 \\
\hline Nyanza & 90.8 & 73.9 & 58.0 & 80.6 & 108.4 \\
\hline Nyarugenge & 179.5 & 189.3 & 154.4 & 204.8 & 138.4 \\
\hline Nyaruguru & 88.1 & 89.6 & 107.2 & 140.9 & 133.0 \\
\hline Rubavu & 105.6 & 128.9 & 134.5 & 174.4 & 180.1 \\
\hline Ruhango & 81.5 & 87.1 & 69.3 & 90.7 & 111.0 \\
\hline Rulindo & 97.4 & 121.3 & 143.0 & 244.7 & 252.8 \\
\hline Rusizi & 119.6 & 128.1 & 123.7 & 143.6 & 159.5 \\
\hline Rutsiro & 141.5 & 150.3 & 131.7 & 164.5 & 161.2 \\
\hline Rwamagana & 118.9 & 102.6 & 102.8 & 123.0 & 116.8 \\
\hline Average incidence rate & 116.5 & 125.4 & 113.1 & 140.32 & 143.0 \\
\hline
\end{tabular}

Page $4 / 11$ 


\section{Purely Spatial Cluster}

In 12 of total 30 districts (40\%), excess risk of childhood diarrhea was reported (Fig. 1). Excess risk is expressed as a ratio of the number of observed cases over expected cases. High excess risk is indicated with a value $(>1)$. The northern and the eastern provinces were most at risk, three out of five districts composing the northern province were reported to be at risk and 4 out of 6 districts composing the eastern provinces. High excess risks were reported in Kirehe district (eastern province), with a Standard Morbidity Ratio (SMR) of 2.15 with a Relative Risk (RR) = 2.24, and Burera district (northern province), $\mathrm{SMR}=1.63$ with a $\mathrm{RR}=1.66$

Purely spatial clusters were identified without considering time. The clusters occurred in all provinces and the City of Kigali, seven clusters from nine locations were identified countrywide. The most likely cluster occurred in Kirehe district of the eastern provinces, with RR = 2.24 ( $p<0.001)$ and secondary cluster observed in three out of the five districts of the northern province, Burera, Musanze and Gakenke, Log-Likelihood Ratio (LLR) = $9802.70(p<0.001)$. Least clusters occurred in southern province, in only one out of eight ( $1 / 8)$ districts making up the province (Table 2$)$.

Table 2

Distribution of spatial clusters of diarrhoea in children < 5 years in Rwanda between January 1, 2014 and December 31,2018

\begin{tabular}{|c|c|c|c|c|c|c|c|c|c|c|}
\hline Cluster & District & Population & Coordinates/Radius & Obs.* & Exp.** & $\begin{array}{l}\text { Annual } \\
\text { case/100000 }\end{array}$ & Obs./Exp. & RR & LLR & $\begin{array}{l}P \\
\text { value }\end{array}$ \\
\hline 1 & Kirehe & 51757 & $\begin{array}{l}\text { 2.275026 S, } \\
30.674212 \mathrm{E} / 0 \mathrm{~km}\end{array}$ & 70560 & 32781.93 & 27269 & 2.15 & 2.24 & 17049.9 & $<0.001$ \\
\hline 2 & $\begin{array}{l}\text { Burera, } \\
\text { Gakenke, } \\
\text { Musanze }\end{array}$ & 158613 & $\begin{array}{l}1.493932 \mathrm{~S}, \\
29.833803 \mathrm{E} / \\
22.29 \mathrm{~km}\end{array}$ & 140272 & 100462.64 & 17689.4 & 1.4 & 1.46 & 7894.5 & $\begin{array}{l}< \\
0.001\end{array}$ \\
\hline 3 & Nyarugenge & 43271 & $\begin{array}{l}1.952494 \mathrm{~S}, \\
30.062399 \mathrm{E} / 0 \mathrm{~km}\end{array}$ & 37442 & 27407.05 & 17307.8 & 1.37 & 1.38 & 1697.95 & $<.001$ \\
\hline 4 & Rutsiro & 49367 & $\begin{array}{l}\text { 1.959969 S, } \\
29.385713 \mathrm{E} / 0 \mathrm{~km}\end{array}$ & 37028 & 31268.45 & 15002.7 & 1.18 & 1.19 & 517.51 & $<0.001$ \\
\hline 5 & Gatsibo & 65846 & $\begin{array}{l}1.617858 \mathrm{~S}, \\
30.382178 \mathrm{E} / 0 \mathrm{~km}\end{array}$ & 48207 & 41705.42 & 14644.1 & 1.16 & 1.16 & 504.13 & $<.001$ \\
\hline 6 & Gisagara & 49041 & $\begin{array}{l}2.598280 \mathrm{~S}, \\
29.838574 \mathrm{E} / \mathrm{Okm}\end{array}$ & 35581 & 31061.58 & 14512.4 & 1.15 & 1.15 & 324.32 & $<.001$ \\
\hline 7 & Rusizi & 60955 & $\begin{array}{l}2.483495 \mathrm{~S}, \\
28.904454 \mathrm{E} / 0 \mathrm{~km}\end{array}$ & 41202 & 38608.04 & 13520.3 & 1.07 & 1.07 & 88.71 & $\begin{array}{l}<.001 \\
0.00\end{array}$ \\
\hline
\end{tabular}

RR: Relative Risk; LLR: Log-Likelihood Ratio; Obs.: number of observed cases within a cluster; Exp.: number of expected cases in a cluster

\section{Purely Temporal Cluster}

Purely temporal clusters were identified taking into account the time only, with the unit of aggregation taken as a month, without considering space, referred to the district as the unit and scanning for clusters with high rates. These exhibited only one significant cluster in all districts $(\mathrm{RR}=1.23, \mathrm{p}=$ 0.001), from June 2017 to September 2018.

\section{Spatiotemporal Cluster}

Clusters of diarrhoeal diseases were identified considering space and time distribution (district, month and the year). In total four spatiotemporal clusters of diarrhoeal diseases in children under five years occurred between January 1, 2014 and December 31, 2018. The most likely primary cluster occurred in Kirehe district, located in eastern province (LLR = 12340.98, $p<0.001$ ) from June 1, 2016 to October 30, 2018. The second cluster occurred in three out of the five districts constituting the northern province, namely Burera, Gakenke and Musanze (LLR = 7413.99, $p<0.001)$ from May 1, 2016 to October 31, 2018. The fourth cluster was observed in several districts of western and southern provinces making up 11 locations $(L L R=889.25, p<0.001)$ from July 1 , to September 30, 2018. The cluster involved districts composing western province (5 out 7 districts) and south province (6 out of 8 districts) (Table 3 ). 
Table 3

Spatiotemporal distribution of diarrhoeal diseases clusters in children $<5$ years in Rwanda from January 2014 and December 2018

\begin{tabular}{|c|c|c|c|c|c|c|c|c|c|}
\hline Cluster & District & Timeframe & Population & Obs.* & Exp.** & Obs./Exp. & $\mathbf{R R}$ & LLR & $\begin{array}{l}\mathrm{P} \\
\text { value }\end{array}$ \\
\hline 1 & Kirehe & $\begin{array}{l}2016 / 6 / 1 \text { to } \\
2018 / 11 / 30\end{array}$ & 51757 & 40419 & 16665.90 & 2.43 & 2.48 & 12340.98 & $<.001$ \\
\hline 2 & Burera, Gakenke, Musanze & $\begin{array}{l}2016 / 5 / 1 \text { to } \\
2018 / 10 / 31\end{array}$ & 158613 & 80000 & 51073.20 & 1.57 & 1.61 & 7413.99 & $\begin{array}{l}< \\
0.001\end{array}$ \\
\hline 3 & Nyarugenge & $\begin{array}{l}2015 / 5 / 1 \text { to } \\
2017 / 10 / 31\end{array}$ & 43271 & 20341 & 13725.91 & 1.48 & 1.49 & 1408.06 & $<.001$ \\
\hline 4 & $\begin{array}{l}\text { Rusizi, Nyamasheke, Karongi, } \\
\text { Nyamagabe, Nyaruguru, Rutsiro, } \\
\text { Huye, Nyanza, Rubavu, } \\
\text { Ruhango,Gisagara }\end{array}$ & $\begin{array}{l}2018 / 7 / 1 \text { to } \\
2018 / 9 / 30\end{array}$ & 573748 & 24900 & 18881.40 & 1.32 & 1.33 & 889.25 & $\begin{array}{l}<.001 \\
0.01\end{array}$ \\
\hline
\end{tabular}

\section{Seasonal patterns of diarrhoeal diseases in children U5 years in Rwanda}

A time bound consisting of 12 months of the year was considered to illustrate results taking into account variability within months. Climate variables (rainfall and temperature) were also included, to elucidate their relationship with diarrhoeal diseases, and to determine its status during rainy and dry seasons.

A bimodal rainfall was identified, increasing from February and reaching a peak in April. A decline took place in the months of May, June, July and August, reaching the lowest in July. It started to increase again from September to November, reaching a peak in November; then it started to decline again. The mean monthly temperature showed fluctuation over 12 months, with a peak in August and a secondary peak in March, reaching the lowest levels in April and November. The incidence of diarrhoeal diseases increased inversely with the rainfall, with high increases observed during the period post-rainy season (dry season) and decline with the increase of rainfall (Fig. 2).

The results of the linear regression analysis showed a statistically significant impact of maximum temperature and mean monthly rainfall on diarrhoeal disease cases. The findings revealed a positive relationship with maximum temperature, whereby the increase in one degree Celsius $\left(1^{\circ} \mathrm{C}\right)$ was associated with an increase of 15 diarrhoea cases $(95 \% \mathrm{Cl}, 9-20, \mathrm{p}<0.001)$. Furthermore, a negative association with mean monthly rainfall was elucidated, an increase in one millimeter $(1 \mathrm{~mm})$ of rainfall was observed to be associated with a decrease of 14 diarrhoeal cases $(95 \% \mathrm{Cl}$, -20 , $-8, \mathrm{p}<0.001)($ Table 4).

Table 4

Relationship between monthly diarrhoea cases counts, rainfall and temperature from January 1, 2014 to December 31,2017

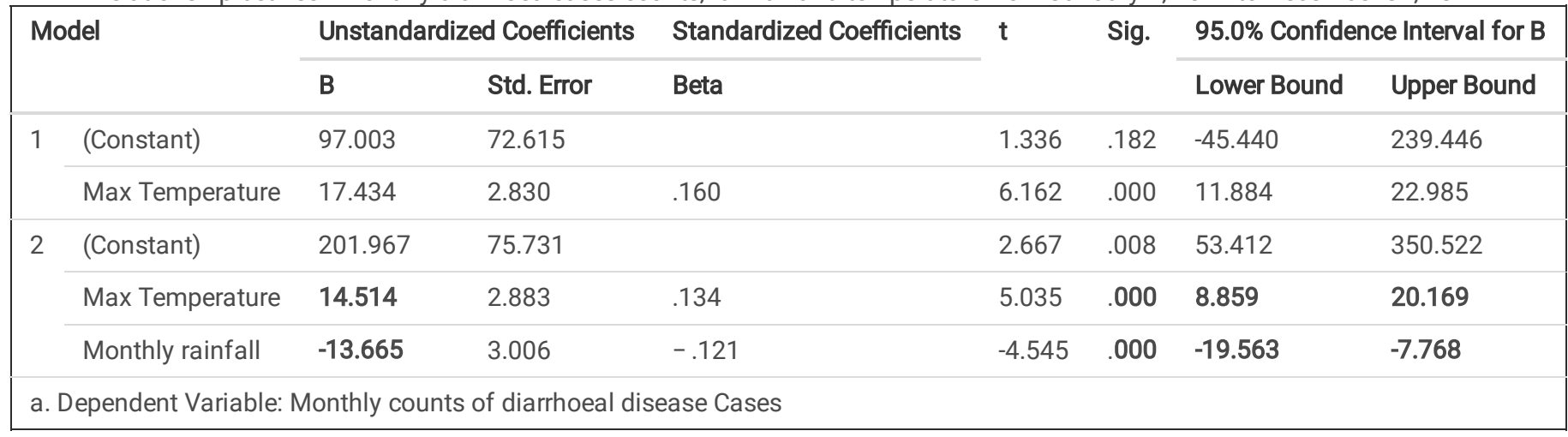

\section{Discussion}

To our knowledge this is the first study to explore space and time along with climatic patterns of childhood diarrhoea in Rwanda at national level. The findings of this study illuminated an increase tendency of diarrhoeal diseases among children under five years in Rwanda over a period of 5 years. The highest incidence rate was reported in 2018. Previous studies conducted in similar setting like in Rwanda contradict with the findings $[20,21]$ whereby they reported a decrease tendency. However another study conducted in Ethiopia found similar findings [16]. Rwanda has made effort to decrease morbidity and mortality of diarrhoeal diseases; in the same context, much have been done to improve and strengthen the health system. The increase in reported diarrhoeal episodes might be explained by the institutionalization of new health facilities at the lowest community level (health posts) and improvement made in health services being provided by CHWs. By increasing access to health services might have increased the uptake of modern health services, which might have resulted in the increasing trend of diarrhoea children aged below five years. 
Spatial Clusters with nonrandom distribution were observed across the country, this may be explained by a disparity of risk factors which may contribute to the disease incidence. The highest excess hazard of diarrhoeal diseases was detected in Kirehe district. This might be explained by the fact that the area experiences long-term drier season and low access to improved drinking water. The recent Integrated Household Living Conditions Survey (EICV) 2016/2017 reported that $8.1 \%$ use surface water in Kirehe, $15.7 \%$ of households use non improved water source. The eastern province where Kirehe district is located was reported as the least fifty in using improved water source (82.6\%) compared to $87.4 \%$ national. The eastern province reported a high proportion of household with low access to improved drinking water $(27.7=72.3$ less than $200 \mathrm{~m}, 53.3=46.7$ less than $500 \mathrm{~m}$ ) in the EICV5 [22].

A temporal cluster was reported between $2017 / 6$ to 2018/9 from all district. This might be due to the facts that new lowest level health facilities (health posts) were initiated increasingly during the past 2 years and might resulted in increased uptake of services.

The finding on seasonality variation considering the 5 years period, diarrhoeal diseases incidence was revealed to begin increasing in May and reaching its peak in July and August. According to the climate variability, this is a drier season observed in Rwanda continuing up to early September prior to rainy season. In addition to that a positively association was observed between increase of maximum temperature and increase of diarrhea cases. Similar findings have been elucidated in different studies [14, 16, 17, 20, 23-25]. The increase cases observed during months with highest temperature justified by plausible explanations; higher temperature promotes the development of and growth of bacteria even though some evidences suggest that the survival and transmission of enteric viruses are increased during low temperature [26]. In addition, during drier season people experiences increased scarcity of improved drinking water which might result in consumption of contaminated water from runoff and sewage overflow happened during rainy season [27].

The decline of diarrhoea incidence rate was observed toward the end on drier season earlier to maximum rainfall. Similar findings have been reported by other researchers showing negative association between rainfall and diarrhoeal diseases [14, 28]. Another study from Ghana reported a negative relationship between diarrhoeal diseases and rainfall by analyzing routine data reported on childhood diarrhoea [29]. The findings of the research that employed secondary data of DHS in Rwanda found that higher runoff was protective of diarrhoea in children living household with unimproved toilet facilities [30]. The DHS 2014/2015 elucidated that only $11.6 \%$ of household used surface water and more than a half of households used improved latrines [31]. This might have reduced the behavior of open defecation and prevented from using surface water during rainy seasons.

\section{Conclusion}

The incidence of diarrhoea in children aged below five years was found increasing and disproportionally distributed across districts composing Rwanda. Findings revealed statistically significant association with climate dynamics. This call for the public attention to climate changes which affect health especially children with age less than five years. In addition, areas with high risk of diarrhoeal diseases were identified and require more attention for prevention and control measures. The finding from this study showed the importance of scan statistics to improve spatiotemporal prediction of climatic changes and associated variation in infectious diseases over space and time scales. This would contribute to the early warning signs for health effects depending on predicted climate changes. Thus, information for this scan statistics proven useful information for planners and decision makers to determine less served area for appropriate allocation of resources in public health interventions targeting diarrhoeal diseases.

\section{Abbreviations}

\section{WHO}

World Health Organization; HMIS:Health Management Information System; NISR:National Institute of Statistics of Rwanda; DHS:Demographic and Health Survey.

\section{Declarations}

\section{Availability of data and materials}

The data sets used in for analysis are not available for the public, but can be obtained through official request addressed to the Rwanda Ministry of Health, HMIS department.

\section{Acknowledgement}

We would like to thank Rwandan Ministry of Health and Rwanda Biomedical Centre for providing data on diarrhoeal diseases and Rwanda Meteorology Agency for providing climatology data. No financial support was received for this research.

\section{Funding}

The study was not funded by any organization. 
LN was involved in study design, data analysis, interpretation and writing the manuscript. ER and PMO participated in study design, interpreted results and made significant revision and contributed to the manuscript. All authors read and approved the final manuscript.

\section{Ethics approval and consent to participate}

The Institutional Review Board of Mount Kenya University, School of Public Health provided ethical clearance on July $24^{\text {th }} 2019$, with REF: MKU04/PGS\&R/0143/2019, i.e. prior to the implementation of the study. In additional an authorization to access data was obtained from Rwanda Biomedical Center, Ref: No 581/RBC/2019 and the Rwanda Meteorology Agency. The study aggregated secondary data, thus consent to participate was not applicable however confidentiality of the information was respected and we did not collect no individual identifiers.

\section{Competing interests}

The authors declare that they have no competing interest

\section{References}

1. World Health Organization. Diarrhoeal disease key facts [Internet]. 2017 [cited 2018 Nov 22]. Available from: http://www.who.int/newsroom/fact-sheets/detail/diarrhoeal-disease.

2. $10.1016 /$ j.pcl.2017.03.006

Kotloff KL. The Burden and Etiology of Diarrheal Illness in Developing Countries. Pediatric Clinics. 2017 Aug 1;64(4):799-814. https://doi.org/10.1016/j.pcl.2017.03.006.

3. 10.1016/S0140-6736(16)31678-6

Vos T, Allen C, Arora M, Barber RM, Bhutta ZA, Brown A, et al. Global, regional, and national incidence, prevalence, and years lived with disability for 310 diseases and injuries, 1990-2015: a systematic analysis for the Global Burden of Disease Study 2015. Lancet [Internet]. 2016 Oct 8;388(10053):1545-602. https://doi.org/10.1016/S0140-6736(16)31678-6.

4. 10.1016/S1473-3099(17)30276-16

Troeger C, Forouzanfar M, Rao PC, Khalil I, Brown A, Reiner RC Jr, Alemayohu MA. Estimates of global, regional, and national morbidity, mortality, and aetiologies of diarrhoeal diseases: a systematic analysis for the Global Burden of Disease Study 2015. Lancet Infectious Disaeses. 2017 Sep 1;17(9):909-48. https://doi.org/10.1016/S1473-3099(17)30276-16.

5. World Health Organization. The top 10 causes of death [Internet]. 2018 [cited 2019 Mar 7]. Available from: https://www.who.int/newsroom/fact-sheets/detail/the-top-10-causes-of-death.

6. 10.1016/S1473-3099(18)30362-1

Christopher, Blacker BF, Khalil IA, Rao PC, Cao S, Zimsen SR, et al. Estimates of the global, regional, and national morbidity, mortality, and aetiologies of diarrhoea in 195 countries: a systematic analysis for the Global Burden of Disease Study 2016. Lancet Infectious Diseases. 2018 Nov 1;18(11):1211-28. https://doi.org/10.1016/S1473-3099(18)30362-1.

7. 10.1016/S1473-3099(18)30362-1nn

Pinzón-Rondón ÁM, Zárate-Ardila C, Hoyos-Martínez A, Ruiz-Sternberg ÁM, Vélez-van-Meerbeke A. Country characteristics and acute diarrhea in children from developing nations: a multilevel study. BMC Public Health. 2015 Aug 21;15:811. https://doi.org/10.1016/S1473-3099(18)30362$1 \mathrm{nn}$.

8. National Institute of Statistics Rwanda. Statistical Year Book 2017 [Internet]. 2017 [cited 2018 Nov 22]. Available from: http://www.statistics.gov.rw/publication/statistical-yearbook-2017.

9. National Institute of Statistics of Rwanda. Rwanda Statistical Year Book 2018. 2018. 11-11 p.

10. Anwar MY, Warren JL, Pitzer VE. Diarrhea patterns and climate: A spatiotemporal Bayesian hierarchical analysis of diarrheal disease in Afghanistan. Am J Trop Med Hyg. 2019;101(3):525-33. https://doi.org/10.4269/ajtmh.18-0735.

11. Ikeda T, Kapwata T, Behera SK, Minakawa N, Hashizume M, Sweijd N, et al. Climatic Factors in Relation to Diarrhoea Hospital Admissions in Rural Limpopo, South Africa. Atmosphere. 2019 Sep;10(9):522. https://doi.org/10.3390/atmos10090522.

12. $10.1289 /$ EHP3711

Mertens A, Balakrishnan K, Ramaswamy P, Rajkumar P, Ramaprabha P, Durairaj N, et al. Associations between high temperature, heavy rainfall, and diarrhea among young children in rural Tamil Nadu, India: A prospective cohort study. Environ Health Perspectives. 2019 Apr 1;127(04):047004 https://doi.org/10.1289/EHP3711.

13. $10.1016 /$ j.ijheh.2019.09.002

Bhandari D, Bi P, Sherchand JB, Dhimal M, Hanson-Easey S. Assessing the effect of climate factors on childhood diarrhoea burden in Kathmandu, Nepal. Int J Hyg Environ Health. 2020 Jan 1;223(1):199-206. https://doi.org/10.1016/j.ijheh.2019.09.002. 
14. Chowdhury FR, Ibrahim QSU, Shafiqul Bari M, Jahangir Alam MM, Dunachie SJ, Rodriguez-Morales AJ, et al. The association between temperature, rainfall and humidity with common climate-sensitive infectious diseases in Bangladesh. PLoS One. 2018;13(6):1-17.

https://doi.org/10.1371/journal.pone.0199579.

15. $10.1007 /$ s00038-019-01285-2

Akinyemi YC. Exploring the spatio-temporal variation in diarrhoea prevalence in under-five children: the case of Nigeria, 1990-2013. Int J Public Health. 2019 Nov 1;64(8):1183-92.https://doi.org/10.1007/s00038-019-01285-2.

16. Beyene H, Deressa W, Kumie A, Grace D. Spatial, temporal, and spatiotemporal analysis of under-five diarrhea in Southern Ethiopia. Tropical Medicine Health. 2018 Dec;46(1):18. https://doi.org/10.1186/s41182-018-0101-1.

17. $10.1186 /$ s12879-017-2611-6 Wangdi K, Clements AC. Spatial and temporal patterns of diarrhoea in Bhutan 2003-2013. BMC Infectious Diseases. 2017 Dec 21;17(1):507. https://doi.org/10.1186/s12879-017-2611-6.

18. 10.1016/j.cegh.2016.07.004

Kumar SV, Devika S, George S, Jeyaseelan L. Spatial mapping of acute diarrheal disease using GIS and estimation of relative risk using empirical Bayes approach. Clinical epidemiology and global health.2017 Jun 1;5(2):87-96. https://doi.org/10.1016/j.cegh.2016.07.004.

19. Kulldorff BM. SaTScan User Guide V9.4. 2018;1-113.

20. Azage M, Kumie A, Worku A, Bagtzoglou AC. Childhood Diarrhea Exhibits Spatiotemporal Variation in Northwest Ethiopia: A SaTScan Spatial Statistical Analysis. PLoS One. 2015;10(12).

21. https://dx.plos.10.1371/journal.pone.0199684

Alebel A, Tesema C, Temesgen B, Gebrie A, Petrucka P, Kibret GD. Prevalence and determinants of diarrhea among under-five children in Ethiopia: A systematic review and meta-analysis. Pietroni M, editor. PLoS One [Internet]. 2018 Jun 28 [cited 2018 Nov 22];13(6):e0199684. Available from: https://dx.plos.org/10.1371/journal.pone.0199684.

22. National Institute of Statistics of Rwanda. The Fifth Integrated Household Living Conditions Survey 2016/2017 [internet]. 2018. 12-14 p.. available from https://www.statistics.gov.rw/datasource/integrated-household-living-conditions-survey-5-eicv-5.

23. Teshima A, Yamada M, Hayashi T, Wagatsuma Y, Terao T. Climate impact on seasonal patterns of diarrhea diseases in Tropical area. University of Kyoto.2004 [cited 2019 Feb 6]. Available from: http://www.hyarc.nagoyau.ac.jp/game/6thconf/html/abs_html/pdfs/T6AT09Aug04093113.pdf.

24. Valcour JE, Charron DF, Berke O, Wilson JB, Edge T, Waltner-Toews D. A descriptive analysis of the spatio-temporal distribution of enteric diseases in New Brunswick, Canada. BMC Public Health. 2016;16(1):1-14. http://dx.doi.org/10.1186/s12889-016-2779-5.

25. Nilima KA, Shetty K, Unnikrishnan B, Kaushik S, Rai SN. Prevalence, patterns, and predictors of diarrhea: a spatial-temporal comprehensive evaluation in India. BMC Public Health. 2018 Dec 23;18(1):1288. https://doi.org/10.1186/s12889-018-6213-z.

26. Braks MA, de Roda Husman AM. Dimensions of effects of climate change on water-transmitted infectious diseases. Air Water Borne Dis. 2013;2(109):2. https://doi.org/10.4172/2167-7719.1000109.

27. $10.1007 /$ s13753-018-0211-8 Abedin MA, Collins AE, Habiba U, Shaw R. Climate Change, Water Scarcity, and Health Adaptation in Southwestern Coastal Bangladesh. International Journal of Disaster Risk Science. 2019 Mar 1;10(1):28-42. https://doi.org/10.1007/s13753-018-0211-8.

28. 10.4269/ajtmh.13-0371

Bhavnani D, Goldstick JE, Cevallos W, Trueba G, Eisenberg JNS. Impact of rainfall on diarrheal disease risk associated with unimproved water and sanitation. American Journal of Tropical Medicine and Hygiene. 2014 Apr 2;90(4):705-11. https://doi.org/10.4269/ajtmh.13-0371.

29. 10.11604/pamj.supp.2016.25.1.6173 Anyorikeya M, Ameme DK, Nyarko KM, Sackey SO, Afari E. Trends of diarrhoeal diseases in children under five years in the War Memorial Hospital-Navrongo, Ghana: 2010-2013. Pan African Medical Journal. 2016;25(Supp 1). https://doi.org/10.11604/pamj.supp.2016.25.1.6173.

30. Mukabutera A, Thomson D, Murray M, Basinga P, Nyirazinyoye L, Atwood S, et al. Rainfall variation and child health: Effect of rainfall on diarrhea among under 5 children in Rwanda, 2010. BMC Public Health. 2016;16(1):1-9. http://dx.doi.org/10.1186/s12889-016-3435-9.

31. National Institute of Statistics of Rwanda. Rwanda Demographic and Health Survey, 2014-2015 [Internet]. 2015.639 p. Available from: http://www.statistics.gov.rw/publication/demographic-and-health-survey-20142015-final-report.

\section{Figures}



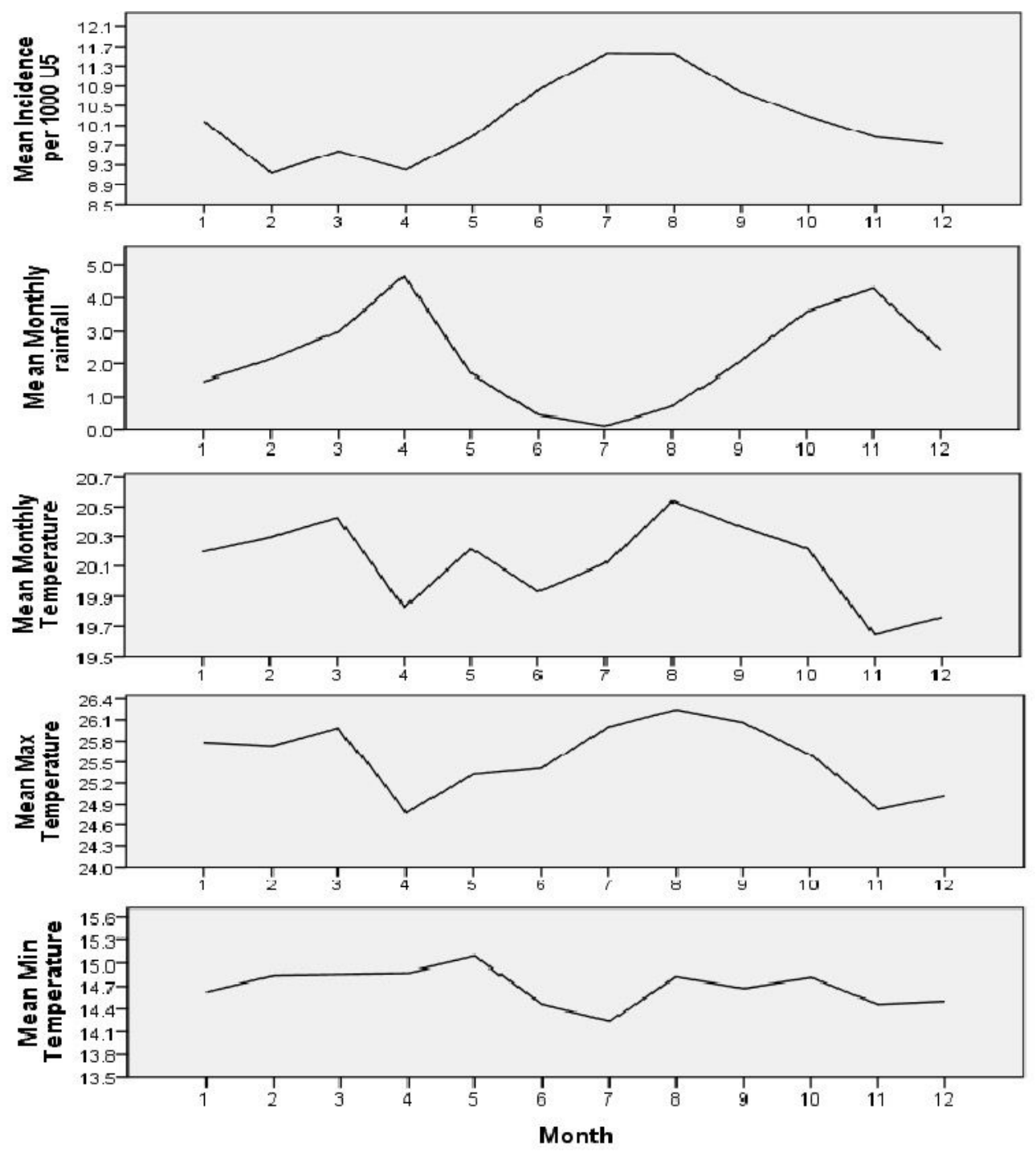

Figure 1

Map of Rwanda showing excess risk (Standard Morbidity Ratio) of diarrhoeal diseases among children younger than five years from each district, January 2014 to December 2018 


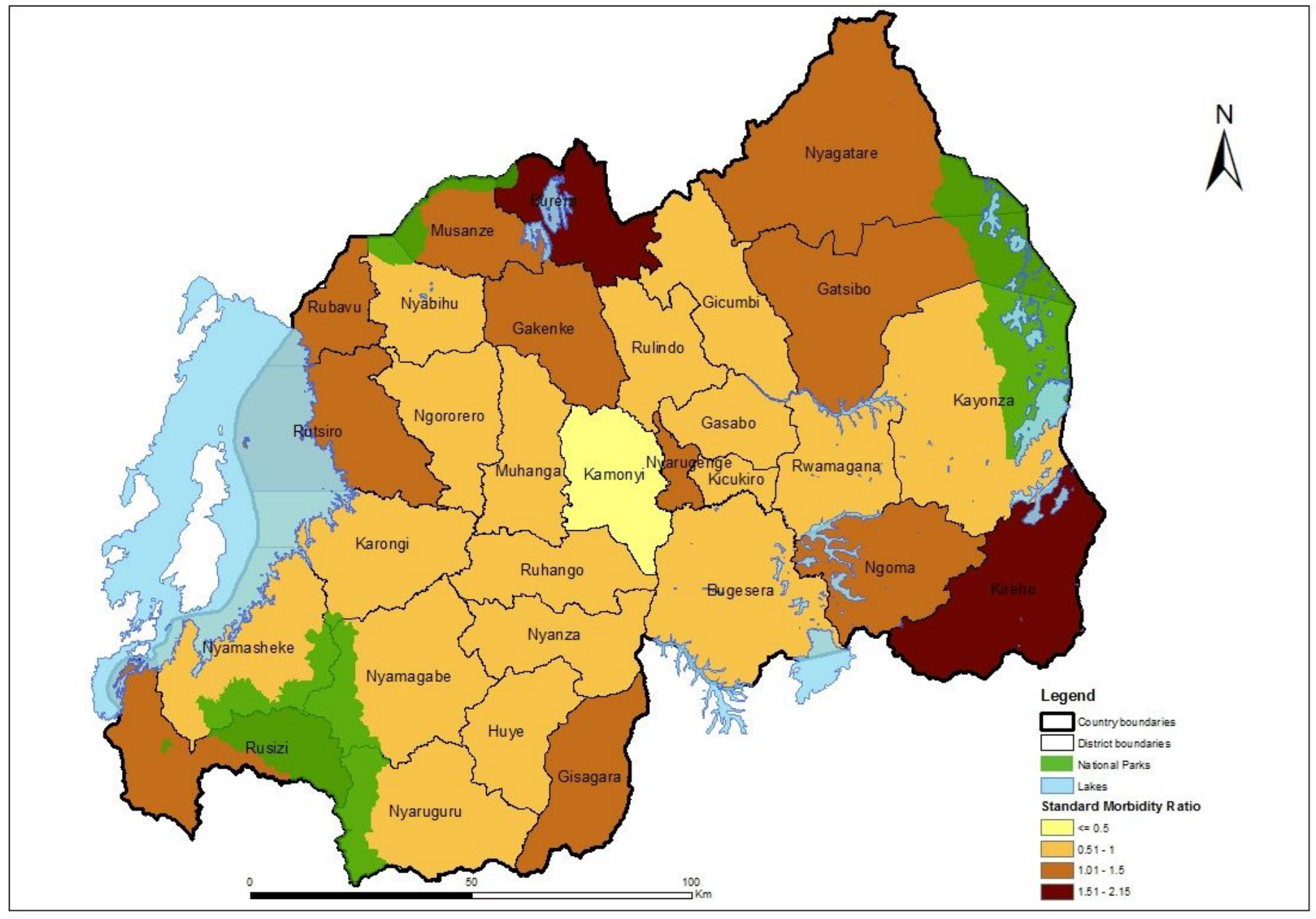

Figure 2

Four years' period of monthly data decomposition on diarrhoeal disease incidence rate, maximum and minimum temperature, and rainfall between January 1, 2014 and December 31, 2017. 